\title{
Index autorum ad Vol. 11
}

\section{Adler, P. 154}

Beckman, L. 106, 126,133, 185, 363

Blehová, B. 52

Book, J.A. 133

Brandtzæg, B. 111, 170

Carvalho, CA.de 217

Cederlöf, B. 338

Cintra, A. B. de Ulhõa 217

Cízková-Pisarovicová, J. 52

Cruz-Coke, B. 58

Dencker, S. J. 265

Eklund, A.-E. 363

Friberg, L. 338

Fudenberg, H. 170

Fuhrmann, W. 289

Gammack, D.B. 1

Goldschmidt, E. 85

Harvald, B. 372

Hauge, M. 265,372

Helmbold, W. 29

Hirschfeld, J. 185

Holmgren, G. 106, 126

Huehns, E.B. 1

Huizinga, J. 137

Hynie, J. 52

Jonsson, E. 338

Kaij, L. 265, 338

Kemp, T. 196

Kirk, B.L. 97

Lai, L.Y.C. 97

Lehmann, H. 1

Lehtovaara, B. 126

Leon, N. 217

Liebrich, K. G. 317

Mäkelä, 0. 126

Mohr, J. 111, 170

Nemeskéri, J. 230

Neto, A .de Suva Coelho 217

Nielsen, A. 178,265 
Nyul,L. 154

Oei, T.L. 205

Pedersen, H 65

Saldanha, P.H. 217

Sammalisto, L. 251

Schwarzfischer, F. 317

Sekla, B. 52

Shooter, E.M. 1

Smårs, G. 133

Smits, M. 137

Solth, K. 162

Stárka, L. 52

Strobel, D. 370

Thoma, A. 230

Zerbin-Büdin, E. 17 